\title{
Reading Comprehension Models of Saudi Non-native Speakers of English
}

\author{
Abdulkhaleq A. Al-Qahtani ${ }^{1}$ \\ ${ }^{1}$ Faculty of Languages and Translation, King Khalid University, Abha, Saudi Arabia \\ Correspondence: Abdulkhaleq A. Al-Qahtani, Department of English, Faculty of Languages and Translation, P. O. \\ Box 9100, Abha 61421, Saudi Arabia. E-mail: aaalqahtani1@kku.edu.sa
}

Received: December 7, 2015 Accepted: December 28, 2015 Online Published: January 31, 2016

doi:10.5539/ijel.v6n1p57 URL: http://dx.doi.org/10.5539/ijel.v6n1p57

\begin{abstract}
The purpose of the present study is to explore the dominant reading model employed by Saudi Arabian readers of English, in response to claims by some researchers, which second language-reading model employed by ESL/EFL learners could be explained from their early literacy practices in their own cultures. Perry (1996), for example, asserted that culture affects learners' reading strategies. She provided empirical findings, which stipulated that cultures affect the kind of reading strategies that learners use. Thus, this paper presents counterevidence that the main reason for strategy choice is not necessarily conditioned by early literacy practices of a given society. Three Saudi informants were asked to describe their reading activities using a retrospection technique. The results show that those informants have employed a reading model that does not comply with Perry's conclusions. They mainly used a top-down approach to reading rather than employing the bottom up model as their early literacy practices implied.
\end{abstract}

Keywords: applied linguistics, reading strategies, reading models, top-down reading model, bottom-up reading model, reading comprehension

\section{Introduction}

Reading in a second language is a very complex task. The reading process itself constitutes a major worry to teachers and researchers alike. Teachers have been experiencing all sorts of difficulties in promoting the reading abilities of their students. They resort to scientific research to find guidance and explanations for their questions.

Researchers have been trying to create a theory that describes the process of reading. As a result of this effort, three major models of reading have been identified in the field of English as a second/foreign language (ESL/EFL): the bottom-up model which was prevalent during the 1960s and revised by Gough (1972); the top-down model developed from the research of Goodman (1967); and the interactive model evolved from the work of Rumelhart (1977, 1981), Clarke (1979), and Carrell (1983).

The bottom-up model (the oldest of the three models) views reading as a chain process. The reader starts by recognizing/decoding the written text at the letter level, then the syllable, words, sentences, and at last at the discourse level. In the linear movement of this model, it seems that readers need to move from one level to the next without interruption. The faster the decoding process of the meaning of words and their components, the more proficient readers become and, consequently, more comprehension is attained (Pressley, 2000). In other words, any break in the chain could result in a failure of the reading task, i.e., an unknown word would impede the successful understanding of a whole sentence. Therefore, an ESL learner must be all-knowing of all syllables, words, sentence structures, and paragraph structures to complete a reading task successfully.

This strict, unrealistic stance held by the bottom-up model raised many questions for researchers. There is little likelihood for an ESL/EFL learner to know every word in a text. In addition, it is hard to expect learners to go through this tedious process from letter level to discourse level. Goodman (1967) introduced the top-down model. This model is the counterpart of the bottom-up model. Readers handle texts initially in light of their background knowledge and their expectations of the text. Then their familiarity with samples of the words in the text helps them to guess, to predict, and to reconstruct the meaning of the text. Therefore, the top-down approach is also called the psycholinguistic guessing game. 
This model was well received by people researching ESL/EFL reading. Whole curricula were built based on the top-down model (Grabe, 1988). However, this model neglects the contributions that knowledge of single words and clause structures offer to the comprehension of the reading texts. Mazzone (2105) describes this model as "goal representations [that] are part of our repertoire of schemata in memory and they can contribute to determine context via backward inferences" (p. 12). This is because communication (written and/or spoken) is essentially a goal-oriented activity. However, this is a bottom-up model strength. Therefore, questions about the role of the bottom-up processing were raised (Clarke, 1979; Coady, 1979).

Towards the end of the seventies and early eighties, researchers like Rumelhart (1977, 1981), Clarke (1979), and Carrell (1983) realized that reading employs both top-down and bottom-up processes. Consequently, a new model has emerged; it is called the interactive model. In this model, both earlier models are employed. The model acknowledges what the reader brings along to the reading including reading skills, world knowledge, and/or linguistic knowledge.

Within the interactive model, researchers found that good readers and poor readers vary in the use of the two processes. Stanovich (1980) identified an interactive-compensatory model. In this subsection of the general interactive model, Stanovich contended that readers who lack knowledge required by one reading process, say the bottom up, would shift to the other reading process, the top-down, to compensate for that deficiency. Stanovich asserted that poor readers use the top down process more frequently; the top down process compensates for gaps in readers' knowledge. The two processes, therefore, compensate for each other (Carrell, 1984; Eskey, 1988). More recent research provided sufficient evidence that the degree of using either process (top down or bottom up) is related to the degree of reading proficiency not only among non-native speakers but also among native speakers (Sheory \& Mokhtari, 2001).

In the domain of the interactive model, as the most recent and accepted model of reading, a whole lot of variables come into play such as L1, exact learning strategies, literacy, and the type of text. To begin with literacy as a variable, researchers paid very close attention to how literacy is developed in a second language. McKay (1993) contended that literacy in L1 correlates with literacy in L2. This type of relationship explains the rationale that researchers maintain for building on the findings in research of L1 reading, for example, Bernhardt (2000) among others considered research in L2 reading as a continuation of the research in L1 reading.

Based on the interactive model of reading and the conclusions researched by Stanovich (1980, 1984), Carrell (1983), and Eskey (1988), the cultural variable was introduced and researched. Perry (1996) conducted an interesting study that compares two different cultures: Chinese and Nigerian. Her goal was to see if different cultures employ different reading processes.

The data of the study were collected in Nigeria and in China. The subjects were two groups of Nigerian and Chinese students. Perry observed that the Nigerian group employed more of the top down process, while the Chinese showed use of the bottom up process. She reported that the Chinese worked from the word level to the sentence level before they were able to relate the message to their own experiences. On the other hand, the Nigerians exhibited top down "strategy" early on.

Perry (1996) provided empirical findings that culture affects the kind of reading strategies that learners use. The Nigerian students used a top-down reading strategy. According to Perry that was because of their cultural environment where they had to rely on the context to infer meanings from the received messages, due to the many different dialects and languages surrounding those students.

Perry also capitalized on the impact of early literacy practices in the two cultures. In Nigeria, children do not encounter the written text very often. Usually, children do not handle reading material anywhere but in schools. On top of that, the majority of children do not go to school until they are around ten years old. The lack of interaction with the printed words lower their chances of getting acquainted with the constituent parts of the written discourse.

The Chinese students, on the other hand, employed a bottom up reading strategy. That was because of the special early literacy practices imposed by caretakers. Chinese children encounter the written words very early on in their lives. They usually go to preschools to learn reading their orthography. Chinese early literacy practices impose the learning of pictograms (Chinese characters), words, and then sentences.

Perry concluded that, "Nigerians were willing to bring these schemata [top down strategy] into play at a much earlier stage than the Chinese were and at the same time were more tolerant of ambiguity in their interpretation of individual lexical items" (p. 680). Perry claimed adherence to the framework prescribed by Stanovich (1980) and Carrell (1984), which views reading as an interactive-compensatory process. 
Abbott (2006) and Fender (2003) conducted two comparative studies about Arab ESL learners and their Chinese and Japanese learners' counterparts. They both assert that Arab ESL learners employed a top-down reading approach. Both researchers did not acknowledge the differences that could be found within Arab cultures. They ascribed their conclusions to the teaching method of EFL, which they singled out as a main reason for the reading model choice. Abbott contended that EFL in the Arab world is highly student-centered which, allows students to interact and comprehend texts more globally, a position that is not supported by many studies conducted in the Arab world (Al-Qahtani, 2015). In addition, the researchers neglected the fact that their Arab participants might have been influenced by the ESL environment in which they live.

Those reading studies and their findings prompted some questions about the literacy practices and particularities in other cultures, such as the Saudi Arabian culture, for instance. This paper attempts to answer the following two questions:

1. What kind of reading models do Saudi learners/users of English employ?

2. To what extent do Saudi Arabians employ any of the two reading models?

My personal assumption would go for Perry's position. Since, to the best of my knowledge, there are not many studies dealing with this particular issue in a Saudi Arabian context, I draw on my personal experiences and the known (to us) literacy practices in Saudi schools. This is why this study is significant; it is conducted either to support or to refute Perry's claims about cultural role in the learners' choice of a certain reading model.

Consequently, I assumed that Saudi learners would employ a bottom up reading strategy. This position resulted from the facts about Saudis' early literacy practices. At an early stage of children's lives, caretakers introduce the letters of the alphabet as an initial literacy practice. This usually happens during their fourth to fifth years of age. As first graders or earlier in kindergarten, little children start combining letters to form single words. Then, the words are structured to form meaningful phrases followed by whole messages. The whole-message stage does not come until later towards the end of the first year of school. It is worth noting that even when the alphabet is presented to little children, the letters are uttered in a way that is different from their actual use in actual words; a process practiced in US elementary education which Smith (2003) calls unspeakable acts. For example, the letter sound $/ \mathrm{g} /$ is pronounced GAAF while in a word it is just /g/ as GALAM for pen; this resembles English utterances of isolated letters as opposed to their actual pronunciation as part of words, i.e. H pronounced AICH in isolation and $/ \mathrm{h} /$ as in house.

These facts about Saudi culture early practices have led me to believe that it resembles the Chinese as described by Perry (1996). The Chinese employ bottom up reading strategy because they learn their characters first and then join them to form words. Saudi Arabian learners would do similarly. My other question pertains to whether there is greater reliance on one particular model than on the other. As was seen in the literature, the reliance on one model is largely a compensatory process.

I assumed that my participants would display some preference for a bottom-up strategy rather than a top-down approach. Based on Perry's findings, my participants would resemble the Chinese in the sense that the latter have hardly exhibited any top-down activities. Actually, Chinese students would read whole sentences in succession before they are able to establish a connection between the reading and their backgrounds, and so would the Saudis.

\section{The Study}

\subsection{The Participants}

To answer the above questions, I conducted this piece of exploratory research with three Saudi Arabian highly proficient English users. The first one is almost forty-one years old (Participant 1), the second is thirty-one years old (Participant 2), and the third is twenty-nine years old (Participant 3). All of the three had finished and graduated from a US university. They are now faculty members in a major Saudi university.

\section{Participant 1}

Participant 1 received his first classes in English when he was thirteen; this is the time when students are in the seventh grade. He kept attending classes until he finished high school. Throughout the six years (middle and secondary schools), he received two classes a week about English. In Saudi Arabia, students are instructed about English twice a week, mostly in Arabic. He studied Agricultural Sciences in his undergraduate education. In college, he only had three general courses in English. He reported that very few reading assignments were asked of him for those courses. Then he was appointed as a teaching assistant in the same department and pursued a master's degree there. No English courses were required for the masters, but he became aware of the importance 
of the language when he was trying to gain access to the literature of his field written in English.

He moved to the US in 1996 to pursue a doctoral degree in a field of agriculture at a major American university. Upon arrival, he enrolled in the English Language Institute (ELI) where he spent a whole year during which he managed to attain the required TOEFL score for his admission to the university(550 Paper-based). He describes his experience at the ELI as enriching and priceless. By Fall 98, he was a full time student in the doctoral program. He describes his program as very demanding, and as for reading, he claims that he had to read whole books and articles to cope with his degree requirements. He was asked to rate his reading abilities on a scale of 1 to 10 where 1 is very poor and 10 is excellent, and he gave himself a score of 6 .

\section{Participant 2}

Participant 2 went through the exact education system as P 1. He started learning English in his seventh grade and continued until he finished high school. In college, he studied Agricultural Sciences. He became teaching assistant in the same department after graduation. He came to the American university in 1999. He enrolled in the ELI for a whole year. Then he enrolled in the MS program in agricultural engineering. He finished his MS in the Fall 2003 and started a Doctoral program in Spring 2004. He claims that he reads a lot to meet the requirements for his degree. He was asked to rate his reading skills on a scale of 1 to 10 , and he gave himself a score of 7.

\section{Participant 3}

Participant 3 had somewhat different learning experiences from the other two. He was born to a banker and a university professor. He started his life in a housing compound with international expatriates form many different countries. His parents befriended two American families who lived in the same compound; one of the families had a child of the same age as P 3 who became his best friend. P 3 recalled vividly that he used to spend whole weekends with his friend. He attended pre-k, kindergarten, and elementary schools where English is taught as a subject throughout these levels. Student 3, therefore, had dissimilar learning experiences from those of the other two students.

He studied chemistry in college. He took three English courses during his tenure as an undergraduate, just like the other two students; those three courses were a university requirement. Before graduation from college, he enrolled in extensive language training programs inside the country and abroad. He enrolled in five programs one after the other in Riyadh over two summers. Then he left Saudi Arabia for the US during the last summer before graduation. He spent two months in North Carolina in an intensive English language program.

He graduated in spring 97. One year later, he came to the US for graduate studies in chemistry. He did not need to enroll in any of the courses at the ELI because he had the required TOEFL score necessary for admission to the chemistry program. He spent more than six years to earn his degrees. When asked to rate his reading abilities on a scale from 1 to 10 , he awarded himself a score of 8 .

\section{The Procedures}

The study consists of three phases: pre-activity interview, the activity, and a retrospection interview. The pre-activity interview consists of an introduction to the task and three questions. The activity is a reading passage printed out from an American university campus newspaper. The post-activity interview was retrospection questions about their performances in the activity phase.

The main purpose of the pre-activity interview was mainly to collect biographical information and to introduce them to the task. They were given explicit information about the study, but I did not tell them that they needed to retrospect. Their anonymity was guaranteed, as they demanded. The personal questions that I asked were:

1) What is your name, age, major?

2) Did you go to preschool? Tell me about your early experiences with literacy in your L1 and L2.

3) Would you tell me about your EFL learning experience? How did you manage reading tasks in English during the undergraduate college years?

4) How do you go about your readings here as a faculty member to keep abreast of the developments in your area?

The activity is a reading passage from a campus newspaper that is approximately 220 words. The audience is the college student population. The language used in the passage is Standard English. It is a first page report of a dialogue between three interfaith groups. The main message of the passage is to encourage people of different religious backgrounds to live in harmony, and this will only occur when people understand each other. 
I chose this particular passage because I wanted my informants to read authentic materials that are interesting to them, having gone through students' life in the USA themselves. In addition, the message has cultural specific references and I wanted to see how they would deal with ambiguity. The length was appropriate for them given their busy schedules and their hesitation to participate.

The third phase of the study is the retrospection phase. The participants were asked immediately after they finish reading to describe their mental activities as they read. When they finished, I asked them to write what they have just said in Arabic so that I ensure that they have the linguistic skills required to provide accurate descriptions. In addition, I asked the following direct questions:

1) When you find a word, a clause, a sentence that you do not know, do you continue as long as you understand what is going on? Elaborate

2) Did you guess the meaning of unknown words?

Since my informants are originally NNS of English, I conducted the interviews in Arabic because I needed them to elaborate as much as possible.

\section{Results}

The three participants were asked the four pre-activity questions about their personal previous learning experiences. Their responses are given in the subjects' description section above. Then each subject was asked to read the passage, I used a stopwatch to measure the time consumed by the activity, but they did not know that I was timing their reading. The students did not know before the reading that they would retrospect after the reading to ensure that their performance is as natural as possible. Each student was asked right after the reading to describe his mental activities as he read the passage. I did not allow much time between their reports and the end of the reading task to ensure a better reliability of the study as Ericsson and Simon (1984) advised. I asked them to do that in Arabic so that they can elaborate and provide a fuller description of their reading processes.

I wrote their descriptions in my notebook. Then I asked them to write what they had just said on a piece of paper. I compared my notes to their written account and found them almost the same. After they finished writing, I asked each one of them the two questions about their strategies when encountering unknown words. I recorded their answers and thanked them for their participation.

The informants seemed to have employed more of the top down reading strategy in contradiction to my initial expectations, as well as to the assumptions in Perry (1996). The data collected suggest a strong reliance on top-down model. I will present a translation of each participant's account of the reading process.

\subsection{Participant 1}

Participant 1 finished reading the passage in two and a half minutes. He said, "I read the article about interfaith. I had a previous idea about the principles on which these interfaith dialogues are based. Once I started reading, I realized that there are lots of what I was expecting in the passage. Actually, the moment I saw the word interfaith in the title I could have predicted what it is all bout.” After finishing his report, I asked him whether he found a word that he did not know and he said that he did not. I asked what he usually did when he found a word that he did not know, and he said that he would guess it from the context. I asked him "What if you were not able to do that?" He said that he would leave it. I wondered about the use of a dictionary, and he said that he does not have time to look up every word he does not know. He admitted the use of dictionary during his first couple of years as a student when he was in his program in the USA but not anymore.

This means that the top-down strategy was the dominant reading strategy. One can clearly see that Participant 1 uses a top-down strategy. He relied heavily on his background knowledge to understand the passage right from the beginning of the activity unlike the Chinese students who would not be able to make the connection until they finish at least a couple of sentences and possibly the whole passage. Participant 1 did not show much evidence of the use of the bottom-up model.

\subsection{Participant 2}

Participant 2 finished reading in approximately two minutes. In his retrospection, he said, "I was looking for anything that contradicts my understanding of interfaith. Everything said in the article conforms to what I already know." I asked him what he meant by saying that he was looking for things that contradicts his expectations, and he said that during the reading he had his background knowledge of interfaith present as he read. Then I asked whether he found an unfamiliar word and he said that he did not. I asked what he usually did when he found one, and he said that he would guess it from the context. I wondered if he would use a dictionary, and he said that he did not usually use a dictionary, but he would if he thought the word is important to know. 
Participant 2 employed the top-down model as Participant 1 . However, the two gentlemen approached the text differently. Participant 1 was reading to confirm his own previous knowledge, while Participant 2 was looking for ideas that contradict his expectations. This means that though Participant 2 employed a top-down model, he employed the bottom-up model to a greater degree than Participant 1 . He was paying closer attention to the text.

\subsection{Participant 3}

Participant 3 finished reading in three minutes. In his report he said, "In the beginning I was concentrating on the word interfaith, I did not know its exact meaning. I broke it apart, and I thought that it might mean something within faith. When I reached the end of the first paragraph, I realized what it actually meant. Then I remembered something about this movement [interfaith]. I had some expectations by the end of second paragraph and the rest of the article confirmed my expectations." As for the question of strategies used with unknown words, he stated that he would break the word into its constituent parts and then he would try to guess its meaning from the context. He also asserted that he would only use a dictionary if he felt that earlier strategies did not work and felt that the word in question is key to the overall understanding of the text. He gave me the word "interfaith" as an example. He elaborated by saying that he always looks to form the big picture and once that picture is formed he would not care much for the details.

Just like the other two participants, Participant 3 employed the top-down approach. However, his usage of the bottom-up approach is greater than the other two. This is evident in his use of this strategy in breaking down the keyword interfaith and his continuous guessing of the meaning from the context until he got it toward the end of the first paragraph. One can see that the prevailing model is the top down because the participant has brought about his background knowledge as he read and as he understood the key word interfaith. However, the bottom up surfaced as a strategy to face ambiguity, as a strategy of problem solving within the larger framework of the top-down model.

\section{Discussion and Conclusions}

My initial assumption that Saudi students would employ a bottom-up model of reading is not confirmed by this study. The participants employed a top down approach instead. Based on that I can conclude that the subjects' early literacy practices when they acquired L1 literacy does not necessarily dictate the reading strategy they would use when tackling a text in their L2. The three participants showed some degree of an interactive model of reading with overt dominance of a top-down approach. Fender (2003) supports the findings of the present study. He found that Arab ESL learners would comprehend their reading by means of relating and integrating the meaning of words into the bigger picture. He contends that ESL Arab learners are, therefore, top-down readers much more than their Japanese ESL learners counterparts who were found to be bottom-up oriented. In addition, the outcomes of this paper are supported by the findings of Abbott (2006). She concludes that Arab ESL learners outperformed their Chinese counterparts in the use of top-down reading strategies.

Thus, as was explained earlier, the Saudi early literacy practices in their L1 implies that the three learners should use a bottom-up reading strategy, as suggested by Perry (1996). In contrast, the participants showed a greater tendency for a top-down approach. The top-down strategies they used were also exemplars of global approach to the goal of the reading rather than being trapped by local words or structures.

The study also provides evidence that the use of bottom up strategies is a sign of higher proficiency. Eskey (1988) contented that readers who rely on the top-down model for accuracy are poor readers; context should be rather used for fluency. Put another way, readers that are more proficient will employ more of the bottom-up approach for their accuracy. We have seen that Participant 1's perception of his reading skills was 6 out of 10, Participant 2 was 7 out of 10, and Participant 3 was 8 out of 10. The degree of bottom up usage correlates perfectly with the participants' self-perceptions. Participant 1 used the bottom-up strategies to the smallest degree, then Participant 2 was a little bit better, and then Participant 3 scored highest. Participant 3 is the most proficient of all according to Eskey; he relied on the bottom up model for accuracy and the top down for fluency. His superiority is further approved by our knowledge of his earlier learning experience; he had exceptional chances in being acquainted with English texts early on in his life.

This study brings up a notion that Perry's (1996) findings about cultural impact on reading model choice are not as clear-cut as suggested in that study. On the other hand, this study confirms Eskey's (1988) assertion that the more advanced readers are those who employ both top-down and bottom-up strategies. The contentions of Perry (1996) are not wholly refuted based solely on this study because of some of its limitations, such as its limited scale. The study is more of a pilot procedure, so care should be taken not to jump to conclusions or generalize findings. Only three participants were examined, so it is better not to generalize this finding until more evidence is gathered in a higher scale study. Therefore, I believe that the findings of this study pave the way for more 
research in this direction.

\section{References}

Abbott, M. (2006). ESL reading strategies: Differences in Arabic and Mandarin speaker test Performance. Language Learning, 56(4), 633-670. http://dx.doi.org/10.1111/j.1467-9922.2006.00391.x

Al-Qahtani, A. (2015). Teacher-centered approach and its ramifications on the performance of would-be professors/teachers: Two case studies of NNSs. King Khalid University Journal of Humanities, 24(1), $29-60$.

Bernhardt, E. (2000). Second-language reading as a case study of reading scholarship in the $20^{\text {th }}$ century. In M. Kamil, P. Mosentthal, \& R. Barr (Eds.), handbook of reading research (Vol. III, pp. 791-811). Mahwah, NJ: Lawrence Erlbaum.

Carrell, P. (1983). Three components of background knowledge in reading comprehension. Language Learning, 32, 183-207. http://dx.doi.org/10.1111/j.1467-1770.1983.tb00534.x

Clark, M., \& Silberistein, S. (1979). Toward a realization of psycholinguistic principles in the ESL reading class. In R. Mackay, B. Barkman, \& R. R. Jordan (Eds.), Reading in a second language (pp. 5-12). Rowley, MA: Newbury House Publishers, INC.

Coady, J. (1979). A psycholinguistic model of the ESL reader. In R. Mackay, B. Barkman, \& R. R. Jordan (Eds.), Reading in a second language (pp. 5-12). Rowley, MA: Newbury House Publishers, INC.

Eskey, D. (1988). Holding in the bottom: An interactive approach to the language problems of second language learners. In P. Carrel, J. Devine, \& D. Eskey (Eds.), interactive approaches to second language reading (pp. 93-100). New York: Cambridge.

Fender, M. (2003). English word recognition and word integration skills of native Arabic-and Japanese-speaking learners of English as a second language. Applied Psycholinguistics, 24, 289-315. http://dx.doi.org/10.1017/S014271640300016X

Goodman, K. (1967). Reading: A psycholinguistic guessing game. Journal of the Reading Specialist, 6, 126-135. http://dx.doi.org/10.1080/19388076709556976

Gough, P. B. (1972). One second of learning. In J. Kavanagh \& I. Matting (Eds.), Language by ear and by eye (pp. 331-358). Cambridge. Mss: MIT Press.

Grabe, W. (1988). Reassessing the term interactive. In P. Carrel, J. Devine, \& D. Eskey (Eds.), interactive approaches to second language reading (pp. 56-70). New York: Cambridge. http://dx.doi.org/10.1017/cbo9781139524513.008

Kaplan, R. (1966). Cultural thought patterns in intercultural education. Language Learning, 16, 1-20. http://dx.doi.org/10.1111/j.1467-1770.1966.tb00804.x

Kern, R. (1994). The role of mental translation in second language reading. Studies in Second Language Acquisition, 16, 441-461. http://dx.doi.org/10.1017/S0272263100013450

Mazzone, M. (2015). Constructing the context through goals and schemata: top-down processes in comprehension and beyond. Frontiers in Psychology, 6, 1-13. http://dx.doi.org/10.3389/fpsyg.2015.00651

Mckay, S. (1993). Agendas for second language literacy. New York: CUP.

Nunan, D. (1992). Research methods in Language learning. Cambridge, UK: Cambridge University Press.

Perry, K. (1996). Culture, literacy, and L2 reading. TESOL Quarterly, 30, 665-692. http://dx.doi.org/10.2307/3587929

Pressley, M. (2000). What should the comprehension instruction be the instruction of? In M. Kamil, P. Mosentthal, \& R. Barr (Eds.), handbook of reading research (Vol. III, pp. 269-284). Mahwah, NJ: Lawrence Erlbaum.

Sheory, R., \& Mokhtari, K. (2001). Differences in the metacognitive awareness of reading strategies among native and non-native readers. System, 29, 431-449. http://dx.doi.org/10.1016/S0346-251X(01)00039-2

Smith, F. (2003). Unspeakable acts: Unnatural practices. Portsmouth, NH: Heinemann.

Smith, P. (1986). The development of reading. In P. Flecher \& M. Garman (Eds.), Language Acquisition (2nd ed., pp. 475-493). Cambridge: Cambridge University Press. http://dx.doi.org/10.1017/CBO9780511620683.027 
Stanovich, K. E. (1980). Towards the interactive-compensatory model of individual differences in the development of reading fluency. Reading Research Quarterly, 16, 32-71. http://dx.doi.org/10.2307/747348

\section{Copyrights}

Copyright for this article is retained by the author(s), with first publication rights granted to the journal.

This is an open-access article distributed under the terms and conditions of the Creative Commons Attribution license (http://creativecommons.org/licenses/by/3.0/). 